\section{(6) OPEN ACCESS}

\title{
Efficacy and safety of an interleukin 6 monoclonal antibody for the treatment of systemic lupus erythematosus: a phase II dose-ranging randomised controlled trial
}

\author{
Daniel J Wallace, ${ }^{1}$ Vibeke Strand ${ }^{2}$ Joan T Merrill, ${ }^{3}$ Serghei Popa, ${ }^{4}$ Alberto J Spindler, ${ }^{5}$ \\ Alicia Eimon, ${ }^{6}$ Michelle Petri, ${ }^{7}$ Josef $S$ Smolen, ${ }^{8}$ Joseph Wajdula, ${ }^{9}$ Jared Christensen, ${ }^{10}$ \\ Cheryl Li, ${ }^{10}$ Annette Diehl, ${ }^{9}$ Michael S Vincent, ${ }^{10}$ Jean Beebe, ${ }^{10}$ Paul Healey, ${ }^{11}$ \\ Sudhakar Sridharan ${ }^{12}$
}

\begin{abstract}
Handling editor Tore K Kvien
- Additional material is published online only. To view please visit the journal online (http://dx.doi.org/10.1136/ annrheumdis-2016-209668)
\end{abstract}

For numbered affiliations see end of article.

Correspondence to Dr Daniel J Wallace, Division of Rheumatology, Cedars-Sinai Medical Center, Los Angeles, CA, 90048, USA; danielwallac@gmail.com

Received 5 April 2016 Revised 30 June 2016 Accepted 11 July 2016 Published Online First 26 September 2016

\section{CrossMark}

To cite: Wallace DJ, Strand V, Merrill JT, et al. Ann Rheum Dis 2017;76:534-542.

\section{ABSTRACT}

Objectives This phase II trial evaluated the efficacy and safety of an interleukin (IL) 6 monoclonal antibody for systemic lupus erythematosus (SLE).

Methods Patients with active disease were randomised to placebo or PF-04236921 $10 \mathrm{mg}, 50 \mathrm{mg}$ or $200 \mathrm{mg}$ subcutaneously, every 8 weeks with stable background therapy. SLE Responder Index (SRI-4; primary end point) and British Isles Lupus Assessment Group-based Composite Lupus Assessment (BICLA) were assessed at week 24. Post hoc analysis identified an enriched population based upon planned univariate analyses. Results 183 patients received treatment (placebo, $\mathrm{n}=45 ; 10 \mathrm{mg}, \mathrm{n}=45 ; 50 \mathrm{mg}, \mathrm{n}=47 ; 200 \mathrm{mg}, \mathrm{n}=46$ ). The $200 \mathrm{mg}$ dose was discontinued due to safety findings and not included in the primary efficacy analysis. The SRI-4 response rates were not significant for any dose compared with placebo; however, the BICLA response rate was significant for $10 \mathrm{mg}$ $(p=0.026)$. The incidence of severe flares was significantly reduced with $10 \mathrm{mg}(n=0)$ and $50 \mathrm{mg}(n=2)$ combined versus placebo $(n=8 ; p<0.01)$. In patients with greater baseline disease activity (enriched population), the SRI-4 ( $p=0.004)$ and BICLA ( $p=0.012)$ response rates were significantly different with $10 \mathrm{mg}$ versus placebo. Four deaths ( $200 \mathrm{mg}, \mathrm{n}=3 ; 10 \mathrm{mg}, \mathrm{n}=1$ ) occurred. The most frequently reported adverse events included headache, nausea and diarrhoea.

Conclusions PF-04236921 was not significantly different from placebo for the primary efficacy end point in patients with SLE. Evidence of an effect with $10 \mathrm{mg}$ was seen in a post hoc analysis. Safety was acceptable for doses up to $50 \mathrm{mg}$ as the $200 \mathrm{mg}$ dose was discontinued due to safety findings.

Trial registration number NCT01405196; Pre-results.

\section{INTRODUCTION}

Systemic lupus erythematosus (SLE) is a chronic, systemic autoimmune disease associated with heterogeneous immunological and clinical manifestations, leading to sporadic and unpredictable flares of multisystem inflammation. SLE has a substantial detrimental impact on health-related quality of life
(HRQOL) and participation in daily activities, including work within and outside the home. ${ }^{1}$

The pleiotropic cytokine interleukin (IL) 6 has a range of biological effects and is primarily produced by monocytes, fibroblasts and endothelial cells, and by $\mathrm{T}$ cells, B cells, keratinocytes and mesangial cells. ${ }^{2}$ IL- 6 acts alone or alongside other cytokines to promote differentiation of $\mathrm{B}$ cells into immunoglobulin-producing cells, as well as proliferation and differentiation of T cells. ${ }^{3}$

The spontaneous production of autoantibodies plays an important role in SLE pathogenesis, ${ }^{4} 5$ which has been attributed to B cell hyperactivity. ${ }^{6}$ Studies suggest that IL-6 is critically involved in the B cell hyperactivity of SLE, and may also mediate tissue damage. ${ }^{7}$ Moreover, IL-6 regulates hepatic synthesis of acute phase reactants, including the inflammatory biomarker $\mathrm{C}$ reactive protein (CRP), ${ }^{8}$ and is involved in the differentiation of $\mathrm{T}$ helper 17 (Th17) cells, which are understood to be pivotal in the induction of autoimmune diseases. ${ }^{9}$ Consistent with these observations, IL-6 production is higher in patients with active SLE than in healthy individuals, and serum IL-6 levels, as well as IL-6 levels measured in skin lesions and the kidney, correlate with disease activity. ${ }^{10-14}$

Targeting IL-6 signalling may offer a novel therapeutic approach for SLE, supported by promising clinical and serological responses observed with the soluble IL-6 receptor inhibitor tocilizumab in a small, open-label phase I study. ${ }^{15}$ In this study, 16 patients with mild-to-moderate SLE received one of three dose regimens of tocilizumab every 2 weeks for 12 weeks. Improvements in disease activity were seen and antidouble-stranded DNA (anti-dsDNA) levels decreased. It was noted that there was a clear dose-related reduction in complement levels and neutrophil count.

PF-04236921 is a fully human immunoglobulin G2 monoclonal antibody that binds and neutralises IL-6 as demonstrated in the early phase I trials. ${ }^{16}$ Here, we report the results of a phase II doseranging randomised controlled trial to assess the efficacy and safety of PF-04236921 in patients with active SLE. 


\section{METHODS}

\section{Study design}

Following a 4-week screening period, patients were randomised (1:1:1:1) to receive placebo or PF-04236921 $10 \mathrm{mg}, 50 \mathrm{mg}$ or $200 \mathrm{mg}$. Randomisation was performed through an interactive voice response system according to a computer-generated randomisation schedule, with stratification by baseline disease activity (SLE Disease Activity Index (SLEDAI)-2K score 6-9 vs $\geq 10$; anti-dsDNA antibodies greater than vs less than the upper limit of normal $(120 \mathrm{IU} / \mathrm{mL}))$. Doses were administered as two subcutaneous injections at day 1 , week 8 and week 16 over a 24-week double-blind treatment phase, during which efficacy and safety data were recorded. Patients subsequently entered a 28-week follow-up period.

Consistent with entry criteria, stable ( $\geq 30$ days before baseline) standard-of-care SLE medications including immunosuppressives, antimalarials and corticosteroids were allowed. Corticosteroid doses were limited to prednisone $\leq 25 \mathrm{mg} /$ day at baseline. Supplemental corticosteroids were allowed at baseline to no more than $10 \mathrm{mg} /$ day above prestudy doses, but had to be tapered to the baseline dose by day 28. Subsequent dose increases were not allowed thereafter, and tapering was recommended based upon clinical judgement during the treatment phase, however no changes were permitted during the last 4 weeks of the 24-week treatment phase. Rescue medications for disease worsening were allowed during the treatment phase at investigator discretion; however, such patients were considered treatment failures and non-responders for the efficacy analyses.

\section{Entry criteria}

Eligible patients were aged $18-75$ years, had a clinical diagnosis of SLE according to American College of Rheumatology criteria, were serologically positive based upon current or historical positive test results for antinuclear antibodies (ANA, human epithelial type 2 ; titre $\geq 1: 80$ ) and/or anti-dsDNA antibodies (>120 IU/L), and had active disease (SLEDAI-2K score of $\geq 6$ and British Isles Lupus Assessment Group (BILAG) 2004 A disease in $\geq 1$ organ system or BILAG $\mathrm{B}$ disease in $\geq 2$ organ systems if no level A disease activity was present). Detailed exclusion criteria are included in the online supplementary material.

\section{End points}

The primary efficacy end point was the proportion of patients achieving the SLE Responder Index (SRI-4) at week 24.
Responders were defined by a $\geq 4$-point reduction in SLEDAI- $2 \mathrm{~K}$ score, no new BILAG A or two new BILAG B organ domain scores, and no significant deterioration $(<0.3$-point increase) in Physician's Global Assessment score compared with baseline. In addition, responders could not be treatment failures, defined as: new or increased use of corticosteroids after day 28; new or increased use of immunosuppressives and/or antimalarials; death or hospitalisation due to worsening SLE; treatment discontinuation due to SLE; or a flare that would interfere with trial participation.

Key secondary efficacy end points assessed at week 24 included the proportion of patients achieving BILAG-based Composite Lupus Assessment (BICLA) responses (responders defined by BILAG 2004 improvement (all A scores at baseline improved to $\mathrm{B} / \mathrm{C} / \mathrm{D}$ and all $\mathrm{B}$ scores improved to $\mathrm{C}$ or $\mathrm{D}$ ), no new BILAG A scores and $\leq 1$ new $B$ score, no worsening of modified SLEDAI-2K score (modified to omit 'low complement' and 'leukopoenia' parameters), no significant deterioration in Patient's Global Assessment score ( $<10 \%$ worsening), and no treatment failure); $\geq 10 \%, \geq 30 \%$ or $\geq 50 \%$ reductions in anti-dsDNA antibody levels; mean changes in complement levels (C3 and C4); the proportion of patients whose corticosteroid dose was reduced by $\geq 25 \%$ from baseline, and to $\leq 7.5 \mathrm{mg} /$ day, for at least one visit up to and including week 24; mean changes in 36-item Short Form Health Survey (SF-36; V.2) summary and domain scores; mean changes in European Quality of Life 5 Dimensions (EQ-5D) visual analogue scale (VAS) scores; and mean changes in Functional Assessment of Chronic Illness Therapy (FACIT)-Fatigue scores.

Exploratory efficacy end points at week 24 included the incidence of severe SLE flares using modified Safety of Estrogens in Lupus Erythematosus: National AssessmentSLEDAI Flare Index (SFI) or BILAG (defined for this protocol as one new BILAG A or two new BILAG B organ domain scores).

Additional details on pharmacokinetic, pharmacodynamic, biomarker and safety assessments are provided in the online supplementary material.

\section{Post hoc analysis of enriched population}

Prespecified descriptive univariate analyses were performed on the following baseline parameters to identify a population with an increased likelihood of achieving efficacy: age, gender, race, ethnicity, baseline SLEDAI-2K score, corticosteroid use,

Figure 1 Patient disposition. *Treatment group terminated prematurely. $A E$, adverse event.

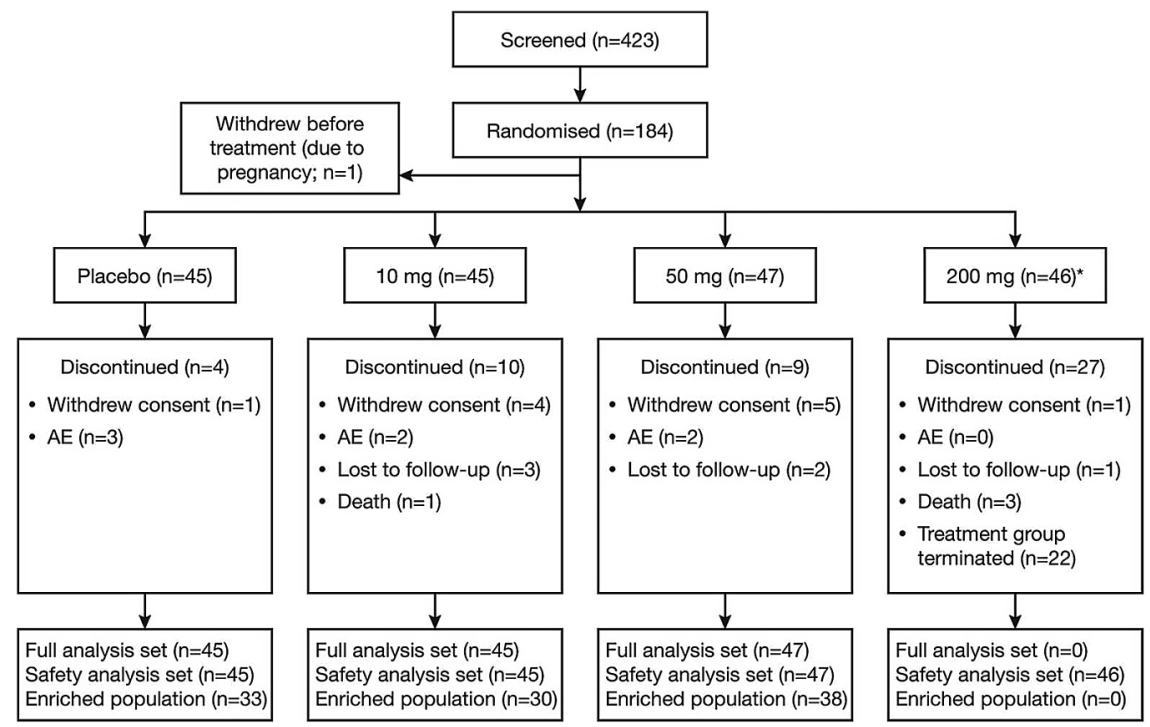


Table 1 Patient demographics and disease characteristics at baseline

\begin{tabular}{|c|c|c|c|c|}
\hline & Placebo $(n=45)$ & $10 \mathrm{mg}(\mathrm{n}=45)$ & $50 \mathrm{mg}(\mathrm{n}=47)$ & $200 \mathrm{mg}(\mathrm{n}=46)$ \\
\hline Mean age, years (SD) & $42.3(13.0)$ & $39.9(11.5)$ & $38.3(10.5)$ & $41.3(11.3)$ \\
\hline Female, n (\%) & $38(84.4)$ & $43(95.6)$ & 43 (93.6) & $43(93.5)$ \\
\hline \multicolumn{5}{|l|}{ Race, $\mathrm{n}(\%)$} \\
\hline White & $33(73.3)$ & $37(82.2)$ & $36(76.6)$ & $33(71.7)$ \\
\hline Black & $4(8.9)$ & $3(6.7)$ & $8(17.0)$ & 9 (19.6) \\
\hline Asian & $1(2.2)$ & $1(2.2)$ & $0(0.0)$ & $0(0.0)$ \\
\hline Other & $7(15.6)$ & $4(8.9)$ & $3(6.4)$ & $4(8.7)$ \\
\hline Mean BMI, kg/m² (SD) & $29.6(7.1)$ & $28.6(6.9)$ & $27.4(6.9)$ & $29.9(8.1)$ \\
\hline Mean SLE duration, years (SD) & $9.1(6.9)$ & $7.9(8.1)$ & $7.5(6.0)$ & $8.6(6.1)$ \\
\hline Mean SLEDAI-2K score (SD) & $9.5(2.2)$ & $9.6(2.7)$ & $9.0(2.7)$ & $10.1(3.9)$ \\
\hline SLEDAI-2K $\geq 10, \mathrm{n}(\%)$ & $22(48.9)$ & $22(48.9)$ & $19(40.4)$ & $22(47.8)$ \\
\hline \multicolumn{5}{|l|}{ BILAG 2004} \\
\hline BILAG $A$ in $\geq 1$ organ system, $n(\%)$ & $20(44.4)$ & $19(42.2)$ & $16(34.0)$ & $25(54.3)$ \\
\hline BILAG $B$ in $\geq 2$ organ systems, $n$ (\%) & $25(55.6)$ & $27(60.0)$ & $33(70.2)$ & $26(56.5)$ \\
\hline Mean BILAG numerical score (SD) & $18.4(3.3)$ & $18.5(4.1)$ & $18.3(4.1)$ & $20.0(5.2)$ \\
\hline \multicolumn{5}{|l|}{ BILAG $A$ or $B$ in organ domain, $n(\%)$} \\
\hline Cardiorespiratory & $0(0.0)$ & $2(4.4)$ & $4(8.5)$ & $6(13.0)$ \\
\hline Constitutional & $3(6.7)$ & $3(6.7)$ & $2(4.3)$ & $1(2.2)$ \\
\hline Gastrointestinal & $0(0.0)$ & $0(0.0)$ & $0(0.0)$ & $0(0.0)$ \\
\hline Haematological & $1(2.2)$ & $0(0.0)$ & $0(0.0)$ & $0(0.0)$ \\
\hline Mucocutaneous & $39(86.7)$ & $39(86.7)$ & $41(87.2)$ & $37(80.4)$ \\
\hline Musculoskeletal & $44(97.8)$ & $45(100.0)$ & $46(97.9)$ & $45(97.8)$ \\
\hline Neuropsychiatric & $0(0.0)$ & $0(0.0)$ & $0(0.0)$ & $5(10.9)$ \\
\hline Ophthalmic & $1(2.2)$ & $0(0.0)$ & $1(2.1)$ & $0(0.0)$ \\
\hline Renal & $1(2.2)$ & $1(2.2)$ & $2(4.3)$ & $3(6.5)$ \\
\hline Mean PhGA score (SD) & $1.6(0.4)$ & $1.7(0.4)$ & $1.6(0.4)$ & $1.8(0.3)$ \\
\hline Serologically positive (ANA $\geq 1: 80$ and/or anti-dsDNA $>120 \mathrm{IU} / \mathrm{mL}$ ), $n(\%)$ & $36(80.0)$ & $35(77.8)$ & $38(80.9)$ & $32(71.1)$ \\
\hline Anti-dsDNA > ULN (120 IU/mL), n (\%) & $13(28.9)$ & 7 (15.6) & $10(21.3)$ & $11(23.9)$ \\
\hline Detectable anti-dsDNA ( $\geq 28 \mathrm{IU} / \mathrm{mL}), \mathrm{n}(\%)$ & $27(60.0)$ & $28(62.2)$ & $28(59.6)$ & $21(45.7)$ \\
\hline Low C3 (<90 mg/dL), n (\%) & $13(28.9)$ & $12(26.7)$ & $11(23.4)$ & $12(26.7)^{*}$ \\
\hline Low C4 (<16 mg/dL), n (\%) & $10(22.2)$ & $9(20.0)$ & 5 (10.6) & $7(15.6)^{*}$ \\
\hline Corticosteroid use, n (\%) & $31(68.9)$ & $32(71.1)$ & $36(76.6)$ & $34(73.9)$ \\
\hline Corticosteroids $>7.5 \mathrm{mg} /$ day, n (\%) & $23(51.1)$ & $14(31.1)$ & $24(51.1)$ & $18(39.1)$ \\
\hline Immunosuppressive use, n (\%) & $20(44.4)$ & $18(40.0)$ & $21(44.7)$ & $23(50.0)$ \\
\hline Antimalarial use, $\mathrm{n}(\%)$ & $34(75.6)$ & $35(77.8)$ & $34(72.3)$ & $26(56.5)$ \\
\hline \multicolumn{5}{|l|}{ Mean SF-36 score (SD) } \\
\hline PCS score & $34.6(10.2)$ & $34.0(8.0)$ & $34.5(8.4)$ & $33.9(9.6)$ \\
\hline MCS score & $39.9(9.7)$ & $39.6(11.8)$ & $42.7(9.9)$ & $39.2(12.2)$ \\
\hline Physical functioning & $51.4(27.8)$ & $48.6(25.2)$ & $51.3(24.3)$ & $45.0(24.3)$ \\
\hline Role physical & $43.8(26.8)$ & $38.5(24.8)$ & $47.1(21.7)$ & $42.4(25.9)$ \\
\hline Body pain & $39.5(22.5)$ & $37.8(20.3)$ & $39.9(20.8)$ & $36.3(19.6)$ \\
\hline General health & $34.4(18.7)$ & $34.6(19.0)$ & $33.9(11.9)$ & $36.8(18.7)$ \\
\hline Vitality & $35.0(22.1)$ & $38.9(21.4)$ & $41.2(17.8)$ & $37.2(18.6)$ \\
\hline Social functioning & $51.7(25.2)$ & $54.4(24.5)$ & $57.7(22.1)$ & $49.7(24.8)$ \\
\hline Role emotional & $61.3(24.6)$ & $56.5(30.0)$ & $61.2(27.1)$ & $53.6(27.9)$ \\
\hline Mental health & $57.7(18.7)$ & $55.0(20.6)$ & $63.2(16.2)$ & $57.6(21.4)$ \\
\hline Mean EQ-5D VAS score (SD) & $56.7(22.9)$ & $55.2(21.5)$ & $57.6(18.5)$ & $49.8(20.4)$ \\
\hline Mean FACIT-Fatigue score (SD) & $26.0(11.8)$ & $25.9(11.4)$ & $29.4(10.3)$ & $24.7(11.6)$ \\
\hline
\end{tabular}

${ }^{*} \mathrm{n}=45$ for the $200 \mathrm{mg}$ group.

ANA, antinuclear antibody; BILAG, British Isles Lupus Assessment Group; BMI, body mass index; dsDNA, double-stranded DNA; EQ-5D, European Quality of Life 5 Dimensions; FACIT, Functional Assessment of Chronic Illness Therapy; MCS, mental component summary; PCS, physical component summary; PhGA, Physician's Global Assessment; SF-36, 36-item Short Form Health Survey; SLE, systemic lupus erythematosus; SLEDAI, Systemic Lupus Erythematosus Disease Activity Index; ULN, upper limit of normal; VAS, visual analogue scale.

immunosuppressive use, anti-dsDNA antibodies, ANA and hypocomplementaemia. A post hoc analysis was conducted to evaluate whether influential covariates could define a more responsive population.
Statistical analyses

The primary analysis of SRI-4 responders at week 24 was based upon a generalised linear mixed model (GLMM) with stratification variables as covariates for each active treatment versus 
placebo comparison. Forty-five patients per group provided approximately $80 \%$ power to detect a $25 \%$ difference in SRI-4 responder rates between PF-04236921 and placebo at week 24 using a one-sided $\alpha$ of 0.05 . No multiple comparison adjustments were made for multiple doses. Similar modelling was used for the secondary analysis of BICLA responders at week 24. GLMM analyses for SRI and BICLA included all available data before each patient completed week 24 or discontinued. The model likelihood was adjusted for missed visits by discontinued patients based on patients with similar data patterns.

The incidences of severe SFI flares and BILAG flares were compared across treatment groups using Fisher's exact test. Mean changes in EQ-5D VAS, FACIT-Fatigue and SF-36 scores for each active treatment group were compared with placebo using an analysis of covariance model, adjusted for baseline scores.

Efficacy analyses were performed on the modified intentto-treat population, which included all randomised patients who received at least one dose of study drug. After the $200 \mathrm{mg}$ dose was stopped, prior to unblinding, the statistical analysis plan was amended to exclude this dose group from the primary analysis. The safety population included all patients who received at least one dose of study drug.

\section{RESULTS}

\section{Patients}

Of 423 screened patients, 183 were randomised and received treatment (figure 1).
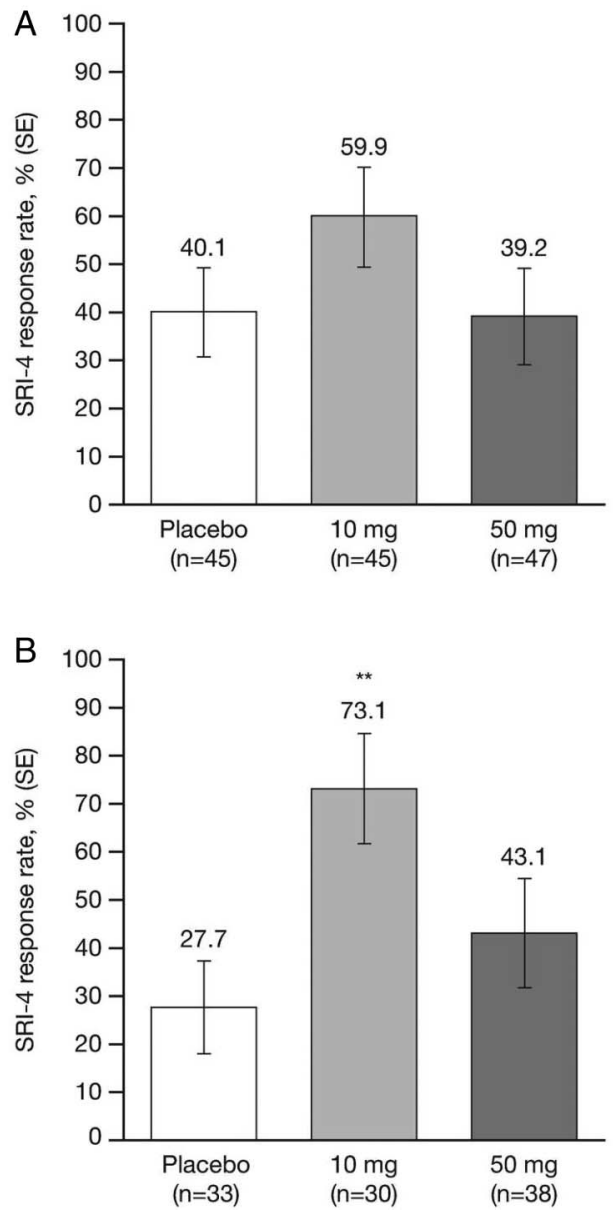

Baseline characteristics were balanced between groups (table 1). Approximately $78 \%$ of patients were serologically positive at baseline; the remaining patients had historically positive ANA or anti-dsDNA, with current active SLE confirmed by independent experts (based upon clinical history and SLE serologies). Rates of discontinuation due to adverse events (AEs), withdrawal of consent and loss to follow-up were generally low across groups (figure 1). Premature termination of the $200 \mathrm{mg}$ dose accounted for 22 of the 50 study discontinuations. Based upon an assessment of fatalities due to serious infections and thromboembolic events, the data monitoring committee advised discontinuation of the $200 \mathrm{mg}$ dose group (see safety outcomes for further details). Therefore, the primary efficacy outcomes are based upon a full analysis set of 137 patients who received placebo, $10 \mathrm{mg}$ or $50 \mathrm{mg}$.

\section{Efficacy outcomes}

SRI-4 response rates (GLMM) at week 24 were numerically greater for $10 \mathrm{mg}$ versus placebo; however, statistical significance was not achieved ( $p=0.076$; figure 2$)$. There were significantly more BICLA responders for $10 \mathrm{mg}$ versus placebo $(p=0.026$; figure 2). Neither outcome was significant for $50 \mathrm{mg}$ versus placebo. A sensitivity analysis was performed for the SRI and BICLA using a logistic regression model; details are included in the online supplementary materials. The observed proportion of responders in the $200 \mathrm{mg}$ group who had completed week 24 prior to premature termination $(n=22)$ was
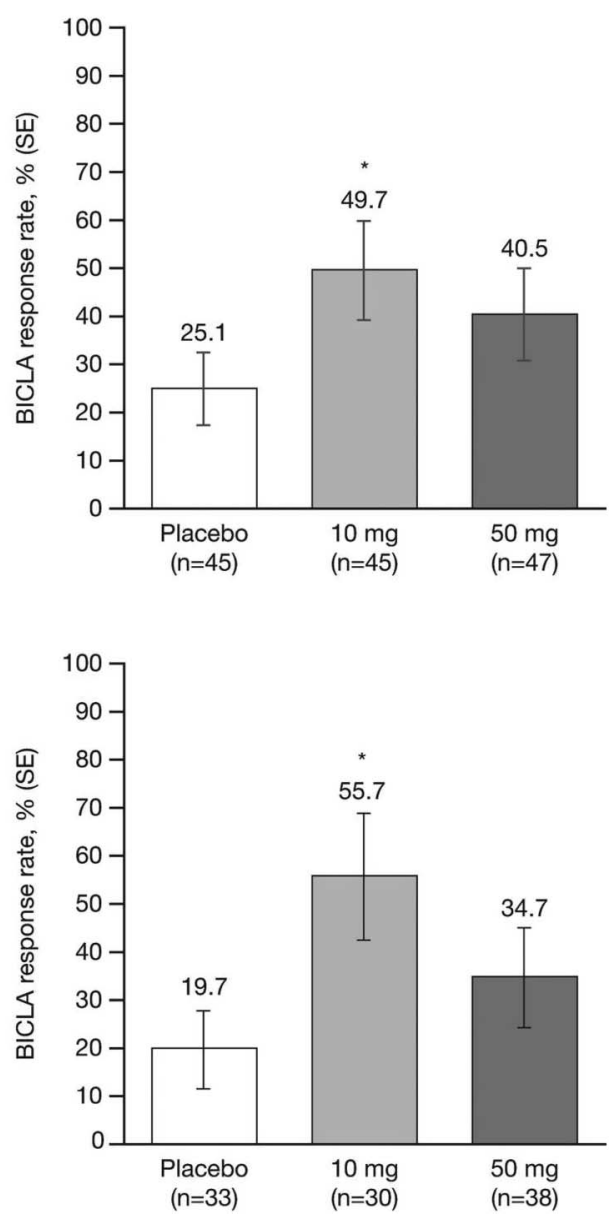

Figure 2 SRI-4 and BICLA responder rates at week $24(\mathrm{~A})$ in the total population, and (B) in the enriched population (GLMM model). ${ }^{*} p<0.05$ vs placebo; ${ }^{*} p<0.01$ vs placebo. BICLA, British Isles Lupus Assessment Group-based Composite Lupus Assessment; GLMM, generalised linear mixed model; SRI, Systemic Lupus Erythematosus Responder Index. 
Table 2 Summary of efficacy outcomes at week 24

\begin{tabular}{|c|c|c|c|}
\hline & Placebo $(n=45)$ & $10 \mathrm{mg}(\mathrm{n}=45)$ & $50 \mathrm{mg}(\mathrm{n}=47)$ \\
\hline $\mathrm{SRI}$ response rate, $\mathrm{n} / \mathrm{N}(\%)^{*}$ & $16 / 42(40.1)$ & 20/35 (59.9) & $14 / 36(39.2)$ \\
\hline OR vs placebo $(90 \% \mathrm{Cl})$ & & $2.2(0.89$ to 5.62$)$ & $0.96(0.38$ to 2.41$)$ \\
\hline $\mathrm{p}$ Value & & 0.076 & 0.528 \\
\hline BICLA response rate, $\mathrm{n} / \mathrm{N}(\%)^{*}$ & $11 / 42(25.1)$ & $18 / 35(49.7)$ & $15 / 36(40.5)$ \\
\hline OR vs placebo $(90 \% \mathrm{Cl})$ & & 2.95 (1.18 to 7.41$)$ & $2.03(0.82$ to 5.06$)$ \\
\hline $\mathrm{p}$ Value & & 0.026 & 0.10 \\
\hline Treatment failures, $\mathrm{n} / \mathrm{N}(\%)$ & $11 / 45(24.4)$ & $1 / 45(2.2)$ & $4 / 47(8.5)$ \\
\hline $\mathrm{p}$ Value & & 0.005 & 0.031 \\
\hline \multicolumn{4}{|l|}{ Patients with disease flares, $\mathrm{n} / \mathrm{N}(\%)$} \\
\hline Severe BILAG flares (new BILAG A or two new BILAG B organ domain scores) & $5 / 45(11.1)$ & $2 / 43(4.7)$ & $0 / 44(0.0)$ \\
\hline Severe SFI flares & $8 / 45(17.8)$ & $0 / 43(0.0)+$ & $2 / 44(4.5)^{\dagger}$ \\
\hline \multicolumn{4}{|l|}{ Proportion of patients with reductions in anti-dsDNA from baseline, $\mathrm{n} / \mathrm{N}(\%) \ddagger$} \\
\hline$\geq 10 \%$ reduction & $7 / 17(41.2)$ & $9 / 15(60.0)$ & $11 / 18(61.1)$ \\
\hline$\geq 30 \%$ reduction & $3 / 16(18.8)$ & $7 / 14(50.0)$ & $6 / 18(33.3)$ \\
\hline$\geq 50 \%$ reduction & $1 / 15(6.7)$ & $4 / 14(28.6)$ & $1 / 16(6.3)$ \\
\hline Mean change in C3 concentration from baseline, g/L (SD)§ & $-0.021(0.176)$ & $-0.100(0.163)$ & $-0.169(0.161)$ \\
\hline Mean change in C4 concentration from baseline, $g / L$ (SD)§ & $0.0002(0.0417)$ & $-0.0096(0.0516)$ & $-0.0551(0.0491)$ \\
\hline \multirow{2}{*}{$\begin{array}{l}\text { Patients whose corticosteroid dose was reduced by } \geq 25 \% \text { from baseline, and to } \leq 7.5 \mathrm{mg} / \mathrm{day} \text {, } \\
\text { for at least one visit up to and including week } 24, \mathrm{n} / \mathrm{N}(\%) \uparrow\end{array}$} & $2 / 23(8.7)$ & $4 / 15(26.7)$ & $5 / 24(20.8)$ \\
\hline & Placebo $(n=45)$ & $10 \mathrm{mg}(\mathrm{n}=43)$ & $50 \mathrm{mg}(\mathrm{n}=46)$ \\
\hline \multicolumn{4}{|l|}{ LS mean change in SF-36 score from baseline (SE) } \\
\hline PCS score & $3.08(1.2)$ & $6.04(1.2)$ & $5.67(1.2)$ \\
\hline MCS score & $2.95(1.4)$ & $2.94(1.4)$ & $2.12(1.4)$ \\
\hline Physical functioning & $4.87(3.4)$ & $10.96(3.5)$ & $12.49(3.4)$ \\
\hline Role physical & $10.62(3.4)$ & $15.28(3.5)$ & $16.06(3.3)$ \\
\hline Body pain & $7.92(3.3)$ & $13.38(3.3)$ & $13.94(3.2)$ \\
\hline General health & $7.01(2.5)$ & $12.53(2.6)$ & $5.15(2.5)$ \\
\hline Vitality & $6.42(3.0)$ & $10.30(3.1)$ & $7.45(3.0)$ \\
\hline Social functioning & $7.62(3.5)$ & $6.78(3.5)$ & $9.58(3.4)$ \\
\hline Role emotional & $6.49(3.4)$ & $6.65(3.5)$ & $10.80(3.3)$ \\
\hline Mental health & $4.90(2.5)$ & $6.96(2.6)$ & $2.72(2.5)$ \\
\hline LS mean change in EQ-5D VAS score from baseline (SE) & $5.99(2.8)$ & $10.30(2.9)$ & $6.18(2.7)$ \\
\hline LS mean change in FACIT-Fatigue score from baseline (SE) & $2.82(1.5)$ & $4.43(1.6)$ & $3.47(1.5)$ \\
\hline
\end{tabular}

Bold italic text denotes changes that were greater than the minimum clinically important difference (SF-36 PCS and MCS $>2.5$-point change from baseline; ${ }^{17}$ SF-36 domain scores $>5$-point change from baseline: ${ }^{17}$ EQ-5D $>10$-point change from baseline; FACIT-Fatigue score $>4$-point change from baseline).

${ }^{*}$ Estimates from generalised linear mixed model. $\mathrm{n} / \mathrm{N}$ represents the observed number of responders $(\mathrm{n})$ for patients who completed through week 24 (N). Patients who discontinued from the study were not included in the denominator. Estimates from the generalised linear mixed model include all available data from completed and discontinued patients. $\mathrm{tp}<0.01$ for combined $10 \mathrm{mg}$ and $50 \mathrm{mg}$ groups versus placebo (Fisher's exact test).

$\ddagger$ Patients with baseline anti-dsDNA above $31 \mathrm{IU} / \mathrm{mL}$ were included in the $\geq 10 \%$ reduction analysis $(\mathrm{n}=50$ ); patients with baseline anti-dsDNA above $40 \mathrm{IU} / \mathrm{mL}$ were included in the $\geq 30 \%$ reduction analysis $(n=48)$; patients with baseline anti-dsDNA above $54 \mathrm{IU} / \mathrm{mL}$ were included in the $\geq 50 \%$ reduction analysis $(n=45)$.

§Patients with complement data were included in the analyses of changes in C3 and C4 concentrations (placebo, $n=41 ; 10 \mathrm{mg}, \mathrm{n}=39 ; 50 \mathrm{mg}, \mathrm{n}=38$ ).

IPatients with a baseline corticosteroid dose $>7.5 \mathrm{mg} /$ day were included in the corticosteroid reduction analysis $(n=62)$.

BICLA, BILAG-based Composite Lupus Assessment; BILAG, British Isles Lupus Assessment Group; dsDNA, double-stranded DNA; EQ-5D, European Quality of Life 5 Dimensions; FACIT, Functional Assessment of Chronic Illness Therapy; LS, least squares; MCS, mental component summary; PCS, physical component summary; SF-36, 36-item Short Form Health Survey; SFI, modified Safety of Estrogens in Lupus Erythematosus: National Assessment (SELENA)-Systemic Lupus Erythematosus Disease Activity Index (SLEDAI) Flare Index; SRI, Systemic Lupus Erythematosus Responder Index; VAS, visual analogue scale.

similar to or worse than placebo for both SRI-4 (18.2\% vs $38.1 \%$ for placebo) and BICLA (27.3\% vs $26.2 \%$ for placebo).

Key efficacy outcomes are summarised in table 2. Treatment failure rates were significantly lower with $10 \mathrm{mg}$ $(\mathrm{p}<0.01)$ and $50 \mathrm{mg}(\mathrm{p}<0.05)$ versus placebo. No patients receiving $10 \mathrm{mg}$, and two receiving $50 \mathrm{mg}$ experienced a severe SFI flare, compared with eight patients receiving placebo; severe SFI flare incidence was significantly lower for pooled $10 \mathrm{mg}$ and $50 \mathrm{mg}$ doses versus placebo $(\mathrm{p}<0.01)$. Severe BILAG flare rates were also lower with PF-04236921 vs placebo, although statistical significance was not achieved. Dose-dependent reductions in C3, C4 and CRP were observed.
Across all groups, mean baseline SF-36 physical component summary (PCS) score (SD) was 34.3 (9.0) and mental component summary (MCS) score was 40.4 (10.9), which were approximately $1.5 \mathrm{SD}$ and $1.0 \mathrm{SD}<$ normative scores of 50 , respectively. ${ }^{17}$ At week 24, trends towards improvements in SF-36 PCS scores, most SF-36 domain scores, FACIT-Fatigue and EQ-5D VAS scores were reported with $10 \mathrm{mg}$ or $50 \mathrm{mg}$ versus placebo. All HRQOL changes from baseline with $10 \mathrm{mg}$ exceeded minimum clinically important differences (MCIDs). ${ }^{18}$

\section{Post hoc analysis of the enriched population}

Four univariate baseline parameters were associated with significant improvements in SRI-4 response rates for $10 \mathrm{mg}$ versus 
Table 3 Summary of efficacy outcomes at week 24 in the enriched population

\begin{tabular}{|c|c|c|c|}
\hline & Placebo $(n=33)$ & $10 \mathrm{mg}(\mathrm{n}=30)$ & $50 \mathrm{mg}(\mathrm{n}=38)$ \\
\hline SRI response rate, $\mathrm{n} / \mathrm{N}(\%)^{*}$ & $8 / 30(27.7)$ & $15 / 21(73.1)$ & $12 / 28(43.1)$ \\
\hline OR vs placebo $(90 \% \mathrm{Cl})$ & & 7.09 (2.11 to 23.85$)$ & $1.98(0.67$ to 5.86$)$ \\
\hline $\mathrm{p}$ Value & & 0.004 & 0.151 \\
\hline BICLA response rate, $\mathrm{n} / \mathrm{N}(\%)^{*}$ & $6 / 30(19.7)$ & $12 / 21(55.7)$ & $10 / 28(34.7)$ \\
\hline OR vs placebo $(90 \% \mathrm{Cl})$ & & 5.11 (1.56 to 16.72$)$ & 2.16 (0.71 to 6.59$)$ \\
\hline $\mathrm{p}$ Value & & 0.012 & 0.127 \\
\hline \multicolumn{4}{|l|}{ Patients with disease flares, $\mathrm{n}(\%)$} \\
\hline BILAG flares (new BILAG A or two new BILAG B organ domain scores) & $5 / 33(15.2)$ & $0 / 30(0.0) \dagger$ & $0 / 38(0.0) \dagger$ \\
\hline \multirow[t]{2}{*}{ Severe SFI flares } & $8 / 33(24.2)$ & $0 / 28(0.0) \dagger$ & $2 / 35(5.7) \dagger$ \\
\hline & Placebo $(n=33)$ & $10 \mathrm{mg}(\mathrm{n}=28)$ & $50 \mathrm{mg}(\mathrm{n}=37)$ \\
\hline \multicolumn{4}{|l|}{ LS mean change in SF-36 score from baseline (SE) } \\
\hline PCS score & $2.80(1.4)$ & 7.60 (1.5)‡ & $5.07(1.3)$ \\
\hline MCS score & $2.04(1.6)$ & $2.69(1.7)$ & $1.56(1.5)$ \\
\hline Physical functioning & $4.62(4.0)$ & $15.09(4.4)$ & $12.44(3.8)$ \\
\hline Role physical & $8.44(3.9)$ & $14.63(4.3)$ & $13.83(3.7)$ \\
\hline Body pain & $6.43(3.9)$ & $17.79(4.2)$ & $11.56(3.7)$ \\
\hline General health & $6.80(2.7)$ & $14.13(3.0)$ & $4.59(2.6)$ \\
\hline Vitality & $3.45(3.5)$ & $12.05(3.8)$ & $4.19(3.3)$ \\
\hline Social functioning & $5.80(4.1)$ & $10.02(4.5)$ & $9.54(3.9)$ \\
\hline Role emotional & $3.62(3.7)$ & $5.89(4.1)$ & $8.98(3.6)$ \\
\hline Mental health & $4.20(3.0)$ & $6.78(3.3)$ & $2.75(2.9)$ \\
\hline LS mean change in EQ-5D VAS score from baseline (SE) & $2.30(3.2)$ & $11.47(3.5)$ & $6.10(3.0)$ \\
\hline LS mean change in FACIT-Fatigue score from baseline (SE) & $1.16(1.8)$ & $5.28(2.0)$ & $3.68(1.8)$ \\
\hline \multicolumn{4}{|c|}{ 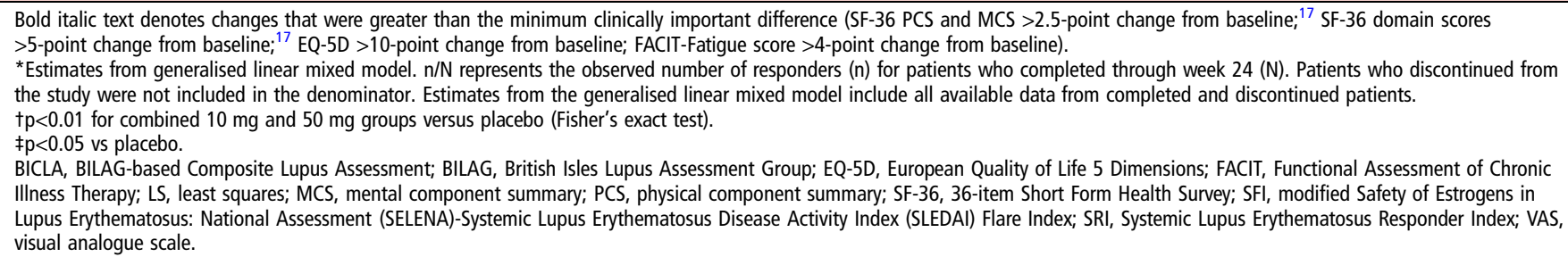 } \\
\hline
\end{tabular}

placebo and defined an enriched population with greater disease activity at baseline: SLEDAI- $2 \mathrm{~K}$ score $\geq 10$, corticosteroids $\geq 7.5 \mathrm{mg} /$ day, anti-dsDNA $\geq 28 \mathrm{IU} / \mathrm{mL}$ or hypocomplementaemia (C3 and C4). This included 101 patients (placebo, $n=33$; $10 \mathrm{mg}, \mathrm{n}=30 ; 50 \mathrm{mg}, \mathrm{n}=38$ ), approximately $74 \%$ of the total population who had one or more of these characteristics.

Efficacy outcomes in the enriched population are summarised in table 3. With $10 \mathrm{mg}$, SRI-4 and BICLA placebo-corrected response rates (GLMM) were greater in the enriched population than in the total population (45.4 vs 19.8 for SRI-4 and 36.0 vs 24.6 for BICLA; figure 2) and significantly different than placebo for both SRI-4 $(p=0.004)$ and BICLA $(p=0.012)$. However, response rates in the $50 \mathrm{mg}$ group were only marginally higher in the enriched population than in the total population. Notably, $10 \mathrm{mg}$ was also associated with significant improvements in SF-36 PCS scores versus placebo $(p<0.05)$ and trends towards improvements in SF-36 MCS and domain scores. Changes from baseline in most SF-36 domain scores, EQ-5D VAS and FACIT-Fatigue scores exceeded MCID.

\section{Safety outcomes}

Rates of deaths, treatment-emergent AEs (TEAEs), serious AEs (SAEs) and AEs leading to treatment discontinuation during the treatment phase are summarised in table 4 . The most frequent TEAEs (excluding infections and injection-site reactions) were headache, nausea and diarrhoea (nausea and diarrhoea were most commonly reported with placebo), and the most frequent infectious TEAEs were upper respiratory infection, cystitis and pharyngitis/laryngitis. More patients experienced non-infectious SAEs with placebo or $200 \mathrm{mg}$ than with $10 \mathrm{mg}$ or $50 \mathrm{mg}$. The higher SAE rate for placebo was largely due to a greater number of SLE flares. Serious infections occurred most frequently with $200 \mathrm{mg}$. There were no cases of herpes zoster or malignancies.

Four deaths occurred during the study. A 32-year-old woman died after receiving a single $10 \mathrm{mg}$ dose due to a suspected pulmonary embolism (PE). A 54-year-old woman experienced severe shortness of breath and died on the way to the hospital after receiving a single $200 \mathrm{mg}$ dose. Two additional patients (a 61-year-old woman and a 24-year-old woman) died after receiving two doses of $200 \mathrm{mg}$ due to infectious causes combined with PEs (sepsis with PE and disseminated tuberculosis with PE). A causal relationship with study medication could not be excluded for any of the events; therefore, the data monitoring committee recommended stopping further dosing of the $200 \mathrm{mg}$ group. Additional details on the deaths are included in the online supplementary materials. In addition to the three deaths due to PEs listed above, there was one additional SAE that was due to a PE in a patient who received placebo.

\section{DISCUSSION}

While none of the treatment arms were significantly different than placebo for the primary end point, results of this trial 


\begin{tabular}{|c|c|c|c|c|}
\hline & $\begin{array}{l}\text { Placebo } \\
(n=45)\end{array}$ & $\begin{array}{l}10 \mathrm{mg} \\
(\mathrm{n}=45)\end{array}$ & $\begin{array}{l}50 \mathrm{mg} \\
(\mathrm{n}=47)\end{array}$ & $\begin{array}{l}200 \mathrm{mg} \\
(\mathrm{n}=46)\end{array}$ \\
\hline Deaths, $\mathrm{n}(\%)$ & $0(0.0)$ & $1(2.2)$ & $0(0.0)$ & $3(6.5)$ \\
\hline $\begin{array}{l}\text { SAEs (excluding infections), } \\
\mathrm{n}(\%)^{*}\end{array}$ & $5(11.1)$ & $2(4.4)$ & $1(2.1)$ & $5(10.9)$ \\
\hline Serious infections, n (\%) & $2(4.4)$ & $1(2.2)$ & $2(4.3)$ & $4(8.7)$ \\
\hline Sepsis & $1(2.2)$ & $0(0.0)$ & $1(2.1)$ & $1(2.2)$ \\
\hline Bronchitis & $1(2.2)$ & $0(0.0)$ & $0(0.0)$ & $0(0.0)$ \\
\hline Tuberculosis & $0(0.0)$ & $0(0.0)$ & $0(0.0)$ & $1(2.2)$ \\
\hline Bronchopneumonia & $0(0.0)$ & $0(0.0)$ & $0(0.0)$ & $1(2.2)$ \\
\hline Cellulitis & $0(0.0)$ & $1(2.2)$ & $1(2.1)$ & $1(2.2)$ \\
\hline Clostridium difficile colitis & $1(2.2)$ & $0(0.0)$ & $0(0.0)$ & $0(0.0)$ \\
\hline Sinusitis & $1(2.2)$ & $0(0.0)$ & $0(0.0)$ & $0(0.0)$ \\
\hline $\begin{array}{l}\text { Any AEs (excluding } \\
\text { infections and ISRs), } \mathrm{n}(\%)\end{array}$ & $34(75.6)$ & $34(75.6)$ & $32(68.1)$ & $31(67.4)$ \\
\hline \multicolumn{5}{|c|}{ Common AEs ( $\geq 5 \%$ in any treatment group, excluding infections and ISR), $n(\%)$} \\
\hline Headache & $2(4.4)$ & $4(8.9)$ & $5(10.6)$ & $5(10.9)$ \\
\hline Nausea & $5(11.1)$ & $2(4.4)$ & $3(6.4)$ & $5(10.9)$ \\
\hline Diarrhoea & $5(11.1)$ & $2(4.4)$ & $2(4.3)$ & $3(6.5)$ \\
\hline SLE & $3(6.7)$ & $3(6.7)$ & $2(4.3)$ & $1(2.2)$ \\
\hline Arthralgia & $3(6.7)$ & $1(2.2)$ & $2(4.3)$ & $2(4.3)$ \\
\hline Dizziness & $2(4.4)$ & $1(2.2)$ & $3(6.4)$ & $2(4.3)$ \\
\hline Cough & $2(4.4)$ & $4(8.9)$ & $0(0.0)$ & $1(2.2)$ \\
\hline Hypercholesterolaemia & $1(2.2)$ & $1(2.2)$ & $4(8.5)$ & $1(2.2)$ \\
\hline Hypertriglyceridaemia & $1(2.2)$ & $1(2.2)$ & $2(4.3)$ & $3(6.5)$ \\
\hline Insomnia & $2(4.4)$ & $1(2.2)$ & $1(2.1)$ & $3(6.5)$ \\
\hline Rash & $1(2.2)$ & $0(0.0)$ & $2(4.3)$ & $4(8.7)$ \\
\hline Hyperglycaemia & $0(0.0)$ & $3(6.7)$ & $0(0.0)$ & $2(4.3)$ \\
\hline Injection-site pain & $1(2.2)$ & $0(0.0)$ & $3(6.4)$ & $2(4.3)$ \\
\hline Pain in extremity & $2(4.4)$ & $0(0.0)$ & $1(2.1)$ & $3(6.5)$ \\
\hline Contusion & $0(0.0)$ & $3(6.7)$ & $1(2.1)$ & $5(2.7)$ \\
\hline Fever & $4(8.9)$ & $0(0.0)$ & $1(2.1)$ & $0(0.0)$ \\
\hline Vomiting & $3(6.7)$ & $1(2.2)$ & $0(0.0)$ & $1(2.2)$ \\
\hline Back pain & $0(0.0)$ & $1(2.2)$ & $0(0.0)$ & $3(6.5)$ \\
\hline Upper abdominal pain & $0(0.0)$ & $3(6.7)$ & $0(0.0)$ & $1(2.2)$ \\
\hline Any infectious AE & $20(44.4)$ & $19(42.2)$ & $23(48.9)$ & $19(41.3)$ \\
\hline \multicolumn{5}{|c|}{ Common infectious AEs ( $\geq 5 \%$ in any treatment group), $n(\%)$} \\
\hline $\begin{array}{l}\text { Upper respiratory } \\
\text { infection }\end{array}$ & $5(11.1)$ & $5(11.1)$ & 5 (10.6) & $10(21.7)$ \\
\hline $\begin{array}{l}\text { Cystitis (urinary tract } \\
\text { infection) }\end{array}$ & $3(6.7)$ & $3(6.7)$ & $3(6.4)$ & $1(2.2)$ \\
\hline Pharyngitis/laryngitis & $4(8.9)$ & $2(4.4)$ & $4(8.5)$ & $0(0.0)$ \\
\hline Sinusitis & $1(2.2)$ & $2(4.4)$ & $3(6.4)$ & $2(4.3)$ \\
\hline Vaginitis & $0(0.0)$ & $4(8.9)$ & $0(0.0)$ & $3(6.5)$ \\
\hline $\begin{array}{l}\text { Discontinuations due to } \\
\text { AEs, } n(\%)\end{array}$ & $3(6.7)$ & $3(6.7)$ & $2(4.3)$ & $2(4.3)$ \\
\hline
\end{tabular}

*SAEs that affected more than one patient: PE (placebo, $n=1 ; 10 \mathrm{mg}, \mathrm{n}=1 ; 200 \mathrm{mg}$, $\mathrm{n}=2$ ), SLE (placebo, $\mathrm{n}=2$ ).

AEs, adverse events; ISR, injection-site reaction; PE, pulmonary embolism; SAEs, serious AEs; SLE, systemic lupus erythematosus; TEAEs, treatment-emergent AEs.

indicate that there was improvement measured in the primary and key secondary end points with the $10 \mathrm{mg}$ dose. The placebo-corrected effect size on the SRI-4 at week 24 for the $10 \mathrm{mg}$ dose was $19.8 \%(p=0.076)$, and the hypothesis that this could reflect a clinically meaningful difference is supported by significant differences from placebo in BICLA response rate and severe SFI flare incidence. No severe SFI flares were reported for $10 \mathrm{mg}$ compared with eight flares for placebo. This is particularly relevant as severe flares are a major cause of hospitalisation and are associated with significant morbidity and mortality. ${ }^{19}$ Trends towards improved HRQOL were reported with $10 \mathrm{mg}$ by SF-36 PCS, FACIT-Fatigue and EQ-5D. Although a greater percentage of patients receiving $10 \mathrm{mg}$ or $50 \mathrm{mg}$ achieved $\geq 10 \%$ decreases in anti-dsDNA antibodies from baseline versus placebo, applying a higher level of response $(\geq 30 \%$ or $\geq 50 \%$ ) did not reveal a clear effect. Dose-dependent decreases in complement were noted, consistent with results with another IL-6 inhibitor. ${ }^{15}$

To determine if there was a subgroup of patients with higher response rates, a post hoc analysis of patients with high disease activity at baseline was performed. Efficacy of $10 \mathrm{mg}$ appeared more pronounced in this enriched population based upon significantly greater SRI-4 and BICLA response rates versus placebo, with a significant reduction in severe SFI flares and improvements in SF-36 PCS scores, despite a smaller number of patients. This is consistent with observations from previous SLE trials that greater discrimination from placebo can be achieved in patients with higher baseline disease activity. ${ }^{20} 21$

Efficacy findings did not follow a classical monotonic dose-response relationship. This atypical pattern could be interpreted as biphasic or U-shaped, which is not completely unprecedented as similar dose-response relationships have been reported in phase II trials of belimumab ${ }^{22}$ and epratuzumab ${ }^{23}$ and in a phase III trial of tabalumab ${ }^{24}$ in patients with SLE. The mechanism by which the higher doses appeared to have minimal efficacy is uncertain. It is possible that larger reductions in CRP and complement with these doses may be detrimental to innate immune regulation and clearance of apoptotic debris. ${ }^{25}$ Alternatively, excessive inhibition of IL- 6 signalling could in turn inhibit induction of suppressor of cytokine signalling 3 , which attenuates the inflammatory effects of IL- $6 .^{26}$ A third potential explanation is that higher doses of PF-04236921 may unfavourably change the balance between regulatory T cells and Th17 cells. ${ }^{9}{ }^{27-29}$ Greater inhibition of IL-6 may interfere with regulatory T cell function, counterbalancing the favourable effects on Th17 cells. Additionally, the small sample size and inherent variability of the SRI may have contributed to the imbalance in results.

It was determined that the safety of the $200 \mathrm{mg}$ dose was not acceptable based upon the deaths that were associated with serious infections and thromboses. An apparent dose dependency was observed for the incidence of death and serious infections. The increase in serious infections for $200 \mathrm{mg}$ in this trial may reflect a high degree of immunosuppression and the possible detrimental impact on innate immune regulation, as considered above. The possible relationship of IL- 6 inhibition with higher thromboembolic disorder rates is not understood, but it should be noted that this trial represented a small sample size and venous thrombosis is common in SLE. ${ }^{30}$ In contrast, the safety profile appeared to be acceptable with $10 \mathrm{mg}$ and $50 \mathrm{mg}$, with similar rates of serious infections to placebo. The pattern of safety events at these doses was generally consistent with the known pharmacology of IL-6 inhibition. The rates of serious infections in other recent lupus trials ${ }^{22} 2431-35$ ranged from $4.3 \%$ to $8.3 \%$, which is comparable to the rates seen in the $10 \mathrm{mg}(2.2 \%)$ and $50 \mathrm{mg}(4.3 \%)$ arms in this study. Although the rate of death in the $10 \mathrm{mg}$ arm $(2.2 \%)$ is higher than the rates in these lupus trials $(0.0-1.9 \%)$, the small sample size complicates its interpretation.

Limitations to the data presented here include the short duration of treatment, which does not allow characterisation of the long-term safety profile, and the post hoc nature of the enriched population analysis. Additionally, potential changes in corticosteroid doses between study visits could impact the 
interpretation of results. The method of imputing missing data could lead to an overestimation of the results when compared with a non-responder analysis.

In summary, this trial supports the rationale for targeting the IL-6 pathway in SLE, however, caution must be taken with regard to safety with higher doses possibly due to increased immunosuppression. The $10 \mathrm{mg}$ dose suggested efficacy in several key clinical end points, however, this was not observed with the $50 \mathrm{mg}$ and $200 \mathrm{mg}$ doses. In a post hoc analysis using a population with greater disease activity at baseline, there was a greater magnitude of effect seen with the $10 \mathrm{mg}$ dose. Further work is required to better define the benefit-risk of this agent.

\section{Author affiliations}

'Division of Rheumatology, Cedars-Sinai Medical Center, Los Angeles, California, USA

2Division of Immunology/Rheumatology, Stanford University, Palo Alto, California, USA

${ }^{3}$ Department of Pharmacology, Oklahoma Medical Research Foundation, Oklahoma City, Oklahoma, USA

${ }^{4}$ Republican Clinical Hospital, Chisinau, Moldova

${ }^{5}$ Centro Medico Privado de Reumatologia, Tucuman, Argentina

${ }^{6} \mathrm{CEMIC}$, Buenos Aires, Argentina

${ }^{7} J o h n s$ Hopkins University School of Medicine, Baltimore, Maryland, USA

${ }^{8}$ Division of Rheumatology, Department of Medicine 3, Medical University of Vienna, Vienna, Austria

${ }^{9}$ Pfizer Inc, Collegeville, Pennsylvania, USA

${ }^{10}$ Pfizer Inc, Cambridge, Massachusetts, USA

${ }^{11}$ Pfizer Inc, Groton, Connecticut, USA

${ }^{12}$ PPD Inc, Rockville, Maryland, USA

Acknowledgements The authors thank the study participants, the investigators and the team. Editorial support under the direction of the authors was provided by Hannah FitzGibbon, PhD, of Complete Medical Communications.

Contributors DJW, VS, JTM, AJS, MP, JSS, JW, JC, CL, AD, MSV, JB, PH and SS were involved in the conception and design of the study. DJW, VS, JSS, JC, CL, $A D, M S V, J B, P H$ and $S S$ were involved in the data and statistical analysis of the study. DJW, SP, AJS, AE, MP, AD, PH and SS were involved with the data acquisition for the study. All authors had access to and interpreted the data. All authors discussed and agreed upon the content of the manuscript before writing took place. All authors reviewed and approved the manuscript's content before submission.

Funding This study was sponsored by Pfizer. Editorial support was provided by Hannah FitzGibbon, PhD at Complete Medical Communications and was funded by Pfizer.

Competing interests DJW is a consultant for GlaxoSmithKline, Lilly, Merck Serono and UCB. VS is a consultant for, or received grants or research support from, Amgen, Anthera, Bristol-Myers Squibb, Celgene, GlaxoSmithKline, Lilly, Merck Serono, Mount Tam Biotechnologies, Novartis, Pfizer Inc and UCB. JTM is a consultant for, or received research support from, AbbVie, Anthera, AstraZeneca, Biogen-IDEC Bristol-Myers Squibb, Celgene, EMD Serono, Genentech, GlaxoSmithKline, Lilly, Neovacs, Pfizer Inc, Takeda, Questcor and UCB, and has performed clinical trial services (adjudication, training and/or quality assurance) for Lilly, Pfizer Inc and Xencor. AE is a consultant for, or received grants or research support from, Abbot, Biogen, Bristol-Myers Squibb, GlaxoSmithKline, Janssen, Lilly and Pfizer Inc. JSS is a consultant for, or received grants from, AstraZeneca, GlaxoSmithKline, Pfizer Inc, Roche and Sanofi. JW, JC, CL, AD, MSV, JB and PH are all employees of Pfizer Inc and hold stock or options in Pfizer Inc. SS is a former employee of Pfizer Inc. SP, AJS and MP have no conflicts of interest to report.

Patient consent Obtained.

Ethics approval The protocol was approved by each institutional review board subject to applicable laws and regulations and ethical principles consistent with the Declaration of Helsinki.

Provenance and peer review Not commissioned; externally peer reviewed.

Open Access This is an Open Access article distributed in accordance with the Creative Commons Attribution Non Commercial (CC BY-NC 4.0) license, which permits others to distribute, remix, adapt, build upon this work non-commercially, and license their derivative works on different terms, provided the original work is properly cited and the use is non-commercial. See: http://creativecommons.org/ licenses/by-nc/4.0/

\section{REFERENCES}

1 Gordon C, Isenberg D, Lerstrøm K, et al. The substantial burden of systemic lupus erythematosus on the productivity and careers of patients: a European patient-driven online survey. Rheumatology (Oxford) 2013;52:2292-301.

2 Naka T, Nishimoto N, Kishimoto T. The paradigm of IL-6: from basic science to medicine. Arthritis Res 2002;4(Suppl 3):S233-42.

3 Van Snick J. Interleukin-6: an overview. Annu Rev Immunol 1990;8:253-78.

4 Fauci AS, Moutsopoulos HM. Polyclonally triggered B cells in the peripheral blood and bone marrow of normal individuals and in patients with systemic lupus erythematosus and primary Sjögren's syndrome. Arthritis Rheum 1981;24:577-83.

5 Smith HR, Steinberg AD. Autoimmunity-a perspective. Annu Rev Immunol 1983;1:175-210.

6 Mok CC, Lau CS. Pathogenesis of systemic lupus erythematosus. J Clin Pathol 2003:56:481-90.

7 Tackey E, Lipsky PE, Illei GG. Rationale for interleukin-6 blockade in systemic lupus erythematosus. Lupus 2004;13:339-43.

8 Castell JV, Gómez-Lechón MJ, David M, et al. Acute-phase response of human hepatocytes: regulation of acute-phase protein synthesis by interleukin-6. Hepatology 1990;12:1179-86.

9 Bettelli E, Carrier Y, Gao W, et al. Reciprocal developmental pathways for the generation of pathogenic effector TH17 and regulatory T cells. Nature 2006;441:235-8.

10 Chun HY, Chung JW, Kim HA, et al. Cytokine IL-6 and IL-10 as biomarkers in systemic lupus erythematosus. J Clin Immunol 2007;27:461-6.

11 Herrera-Esparza R, Barbosa-Cisneros 0, Villalobos-Hurtado R, et al. Renal expression of IL-6 and TNF $\alpha$ genes in lupus nephritis. Lupus 1998;7:154-8.

12 Linker-Israeli M, Deans RJ, Wallace DJ, et al. Elevated levels of endogenous IL-6 in systemic lupus erythematosus. A putative role in pathogenesis. J Immunol 1991;147:117-23.

13 Nürnberg $W$, Haas N, Schadendorf D, et al. Interleukin- 6 expression in the skin of patients with lupus erythematosus. Exp Dermatol 1995;4:52-7.

14 Stuart RA, Littlewood AJ, Maddison PJ, et al. Elevated serum interleukin-6 levels associated with active disease in systemic connective tissue disorders. Clin Exp Rheumatol 1995:13:17-22.

15 Illei GG, Shirota Y, Yarboro CH, et al. Tocilizumab in systemic lupus erythematosus: data on safety, preliminary efficacy, and impact on circulating plasma cells from an open-label phase I dosage-escalation study. Arthritis Rheum 2010;62:542-52.

16 Fogel R, Sridharan S, Li C, et al. Safety, pharmacokinetics, and pharmacodynamics of a human anti-IL6 monoclonal antibody PF-04236921 in healthy subjects. Ann Rheum Dis 2013;71(Suppl 3):680

17 Ware JE. User's manual for the SF-36v2 health survey. Lincoln, RI, USA: QualityMetric Incorporated, 1993.

18 Strand V, Crawford B. Improvement in health-related quality of life in patients with SLE following sustained reductions in anti-dsDNA antibodies. Expert Rev Pharmacoecon Outcomes Res 2005:5:317-26.

19 Lee J, Dhillon N, Pope J. All-cause hospitalizations in systemic lupus erythematosus from a large Canadian referral centre. Rheumatology (Oxford) 2013:52:905-9.

20 Furie RA, Leon $\mathrm{G}$, Thomas $\mathrm{M}$, et al. A phase 2, randomised, placebo-controlled clinical trial of blisibimod, an inhibitor of B cell activating factor, in patients with moderate-to-severe systemic lupus erythematosus, the PEARL-SC study. Ann Rheum Dis 2015;74:1667-75.

21 van Vollenhoven RF, Petri MA, Cervera R, et al. Belimumab in the treatment of systemic lupus erythematosus: high disease activity predictors of response. Ann Rheum Dis 2012:71:1343-9.

22 Wallace DJ, Stohl W, Furie RA, et al. A phase II, randomized, double-blind, placebo-controlled, dose-ranging study of belimumab in patients with active systemic lupus erythematosus. Arthritis Rheum 2009;61:1168-78.

23 Wallace DJ, Kalunian K, Petri MA, et al. Efficacy and safety of epratuzumab in patients with moderate/severe active systemic lupus erythematosus: results from EMBLEM, a phase $\mathrm{llb}$, randomised, double-blind, placebo-controlled, multicentre study. Ann Rheum Dis 2014;73:183-90.

24 Isenberg DA, Petri M, Kalunian K, et al. Efficacy and safety of subcutaneous tabalumab in patients with systemic lupus erythematosus: results from ILLUMINATE-1, a 52-week, phase III, multicentre, randomised, double-blind, placebo-controlled study. Ann Rheum Dis 2016;75:323-31.

25 Du Clos TW, Mold C. Pentraxins (CRP, SAP) in the process of complement activation and clearance of apoptotic bodies through Fc $\gamma$ receptors. Curr Opin Organ Transplant 2011;16:15-20.

26 Croker BA, Krebs DL, Zhang JG, et al. SOCS3 negatively regulates IL-6 signaling in vivo. Nat Immunol 2003:4:540-5.

27 Henriques $A$, Inês L, Couto $M$, et al. Frequency and functional activity of Th17, Tc17 and other T-cell subsets in Systemic Lupus Erythematosus. Cell Immunol 2010;264:97-103

28 Kleczynska W, Jakiela B, Plutecka H, et al. Imbalance between Th17 and regulatory T-cells in systemic lupus erythematosus. Folia Histochem Cytobiol 2011:49:646-53. 
29 Korn T, Mitsdoerffer M, Croxford AL, et al. IL-6 controls Th17 immunity in vivo by inhibiting the conversion of conventional T cells into Foxp3+ regulatory T cells. Proc Natl Acad Sci USA 2008;105:18460-5.

30 Chung WS, Lin CL, Chang SN, et al. Systemic lupus erythematosus increases the risks of deep vein thrombosis and pulmonary embolism: a nationwide cohort study. J Thromb Haemost 2014;12:452-8.

31 Furie R, Petri M, Zamani 0, et al. A phase III, randomized, placebo-controlled study of belimumab, a monoclonal antibody that inhibits B Lymphocyte Stimulator, in patients with systemic lupus erythematosus. Arthritis Rheum 2011;63:3918-30.

32 Isenberg D, Gordon C, Licu D, et al. Efficacy and safety of atacicept for prevention of flares in patients with moderate-to-severe systemic lupus erythematosus (SLE): 52-week data (APRIL-SLE randomised trial). Ann Rheum Dis 2015;74:2006-15.
33 Khamashta M, Merrill JT, Werth VP, et al. Sifalimumab, an anti-interferon- $\alpha$ monoclonal antibody, in moderate to severe systemic lupus erythematosus: a randomised, double-blind, placebo-controlled study. Ann Rheum Dis 2016; Published Online First 23 March 2016. doi:10.1136/annrheumdis-2015-208562

34 Merrill JT, van Vollenhoven RF, Buyon JP, et al. Efficacy and safety of subcutaneous tabalumab, a monoclonal antibody to B-cell activating factor, in patients with systemic lupus erythematosus: results from ILLUMINATE-2, a 52-week, phase III, multicentre, randomised, double-blind, placebo-controlled study. Ann Rheum Dis 2016;75:332-40.

35 Navarra SV, Guzmán RM, Gallacher AE, et al. Efficacy and safety of belimumab in patients with active systemic lupus erythematosus: a randomised, placebo-controlled, phase 3 trial. Lancet 2011;377:721-31. 